\section{Issues in \\ Informing Science + Information Technology}

Volume 16, 2019
An Official Publication

of the Informing Science Institute

InformingScience.org

IISIT.org

INSTITUTE

\title{
INTEGRATING DRONE TECHNOLOGY IN STEM EdUCATION: A CASE STUdy TO AsSESS TEACHERS' READINESS AND TRAINING NEEDS
}

Wing Shui $\mathrm{Ng}^{*}$

Gary Cheng

* Corresponding author
The Education University of Hong Kong, Hong Kong

The Education University of Hong Kong, Hong Kong ngws@eduhk.hk

chengks@eduhk.hk

\section{AbstraCT}

Aim/Purpose

Background

Methodology

Findings

Contribution

Drone technology has been increasingly used in education. This paper reports a study of assessing teachers' readiness and training needs for using drone technology in their teaching.

New technology promotes new ways of practices. With the sophisticated design and the affordance to explore our world from a bird's eye perspective, a drone has been increasingly used to support science, technology, engineering, and mathematics education. However, it also brings challenges to teachers to integrate drone technology in their teaching. It is therefore important to obtain a better understanding of various aspects of integrating drone technology in education.

A group of pre-service teachers was engaged in a case study conducted using a designed-based approach. The participants were randomly assigned into three groups. They were required to develop lesson plans with the application of drone technology in teaching. The lesson plans were subsequently analyzed using the TPCK framework to identify teachers' readiness and training needs.

The participants, to a large extent, have sufficient competence to master the skills and knowledge of drone technology and to integrate it into their teaching. However, they were required to strengthen the pedagogical knowledge, subject content knowledge, and technological content knowledge in order to maximize the potential benefits of drone technology in education.

This paper reports the level of readiness and training needs of teachers regarding the use of drone technology in their teaching.

Accepting Editor: Eli Cohen | Received: December 31, 2018 | Revised: February 12, 2019 | Accepted: April 3, 2019.

Cite as: Ng, W. S., \& Cheng, G. (2019). Integrating drone technology in STEM education: A case study to assess teachers' readiness and training needs. Issues in Informing Science and Information Tecbnology, 16, 61-70. https://doi.org/10.28945/4288

(CC BY-NC 4.0) This article is licensed to you under a Creative Commons Attribution-NonCommercial 4.0 International License. When you copy and redistribute this paper in full or in part, you need to provide proper attribution to it to ensure that others can later locate this work (and to ensure that others do not accuse you of plagiarism). You may (and we encourage you to) adapt, remix, transform, and build upon the material for any non-commercial purposes. This license does not permit you to use this material for commercial purposes. 
Recommendations To conduct teacher training regarding the use of drone technology in education, for Practitioners a particular focus should be put on enhancing teachers' pedagogical knowledge, subject content knowledge, and technological content knowledge.

Recommendations Researcher may further explore the strategies to integrate drone technology in for Researchers teaching.

Impact on Society This paper suggests the area of teacher training regarding the use of drone technology in education. The teaching and learning effectiveness could be improved.

Future Research Future research may study the safety issue and ethical issue of using a drone in education.

Keywords drone, unmanned aerial vehicle, teacher education, STEM education, TPCK

\section{INTRODUCTION}

Drone technology was originally developed mainly for military purpose. With the advancement of technology, drones have been increasingly used for various purposes in our daily life (Preble, 2015). Government, organizations, and individuals have begun to exploit various functions of a drone to accomplish specific tasks. A drone, with its sophisticated design and possibility to explore our amazing world from a bird's-eye view, has been recognized as a useful tool for promoting science, technology, engineering, and mathematics (STEM) education. In recent years, educational practitioners have attempted to integrate drone technology in STEM lessons (Petrinjak, 2016). However, the usage of drone technology in education is still at its very early stage. Very few studies can be found with an elaboration of using drone technology in teaching and learning process, and almost no study has addressed teachers' training needs in this area. In this connection, this paper reports a study that assessed the readiness of teachers regarding the use of drone technology in their teaching. The findings also indicate teachers' training needs for applying this newly developed drone technology in their teaching.

\section{LITERATURE REVIEW}

As a drone is a relatively new technology, this section provides an overview of drone technology and its general applications in our daily life. The authors then discuss the recent trend of using drone technology in education and highlight the important issue of teacher training needs. The research questions are stated at the end of this section.

\section{AN OVERVIEW OF DRONE TECHNOLOGY}

A drone refers to an unmanned aerial vehicle or a remotely piloted aircraft. The US Department of Defense (DOD) (2018) defined a drone as an "aircraft that does not carry a human operator and is capable of flight with or without human remote control" (p. 242). The drone technology has been developed since World War I to support military force with the purposes of reconnaissance and missile strikes. The use of drones in the United States is increasing as it helps reduce casualties in wars (Pearcy, 2015). In the two wars fought by America in Afghanistan and Iraq, drones were extensively used as explosive devices to initiate an attack (Pearcy, 2015; Preble, 2015). With the development of technology, the cost of a drone becomes more affordable and civil use of drones has been increasing since 2000 .

Although a standard classification of a drone has not been developed due to the new development of technology, a drone can be classified into different categories based on its attributes. In general, a drone can be classified into the glider type (e.g., Murch, Paw, Pandita, Li, \& Balas, 2011) and the heli- 
copter type (e.g., Kim, 2016). Different aerodynamic designs are adopted in these two types of the drone to enable it to hover aloft. Since a drone of the helicopter type is possible to hover in a fixed position aloft and it is more flexible in its motion, it has been more frequently used by people. Another method to categorize a drone is the number of propellers attached for generating different amount of lift. For example, the tricopter, quadcopter, hexacopter, and octocopter are some drones with a different number of propellers. People may also use other attributes to categorize a drone, such as its size, its flight range, and the equipment attached to a drone (Dronepedia, 2017).

With the capability to fly aloft and the possibility to go into dangerous areas, a drone has been frequently used to complete specific tasks in our daily life. For example, a drone has been used as a lifesaver to locate missing persons on a search-and-rescue mission. It can also penetrate smoke to help fighting a fire. Moreover, a drone is capable to deliver objects to a distant location (Romano, 2014). Many drones nowadays are designed to equip with a camera. It helps the police to conduct a search of criminal in a wide area from a top-down view (Lee, 2016). Since a drone brings a camera into a new birds-eye perspective, aerial photography or videography has been commonly used in commercial video production, news reporting, and scenery photography. On the other hand, controlling a drone can be regarded as a sports activity and international drone racing competitions have been organized in recent years. Another innovative application of drone is to create a light show using multiple drones. Recently, a drone light show in China has broken the Guinness World Record for the most drones flown simultaneously (Lee, 2018). As reflected by these examples, drone technology has provided ample opportunities to improve the working practices in our daily life.

\section{USE OF DRONE TECHNOLOGY IN EDUCATION}

With the sophisticated design of a drone, many educational practitioners have begun to integrate drone technology to enhance learning with a particular focus in STEM education. Some teachers tried to engage students to explore the technology embedded in a drone (Petrinjak, 2016; Preble, 2015; Strimel, Bartholomew, \& Kim, 2017). In their lesson design, the teaching was implemented in engineering or physics classes. The teacher initiated a project to request students to build and fly a drone. In the learning process, the students were able to develop their understanding on building materials, sensors, and control system. The students also learned physics concepts such as friction, lift, weight, thrust, drag, vortex, and stall. Since a drone is able to bring a camera into the sky and fly to some positions that are difficult to reach, it is an extraordinary tool for researchers to carry out scientific research related to our natural environment. For example, the students in the study by Birtchnell and Gibson (2015), and Jordan (2015) were requested to take aerial photos of the landscape in geologic fieldwork and then to interpret the image to identify the geologic patterns. Moreover, some teachers requested students to fly a drone to a high level in the sky to explore the meteorological features (Petrinjak, 2016). On the other hand, learning activity can be designed with the use of a drone to reinforce the learning in class. For example, students were requested to instruct a drone to fly in a specific path using a computer program in order to enhance their programming skills (Petrinjak, 2016). By requesting the students to apply knowledge in an authentic setting, they were more motivated to learn and more engaged in the learning process. Therefore, technology-driven learning has been promoted in the digital age and educational practitioners have been exploring the use of drone technology in education (Carnahan, 2016). As reflected in these studies, a drone has been recognized as a tool that can potentially enhance learning and teaching effectiveness.

It is believed that teachers have developed a certain level of subject knowledge, pedagogical skills, and self-learning ability. They may, to some extent, able to integrate new technology in their teaching. However, the integration of new technology often leads to fundamental questions in the content and pedagogical aspects and even experienced teachers will find it difficult to deal with (Mishra \& Koehler, 2006). Since a drone is a newly developed technology, it is anticipated that teachers may lack related knowledge to use a drone in their class to improve students' learning effectiveness. It, therefore, raises the demand for teacher training in this area regarding how to integrate drone technology in the 
teaching process. Although some studies discussed the considerations for teaching integrated STEM education (e.g., Guzey \& Roehrih, 2012; Stohlmann, Moore, \& Roehrig, 2012), almost no study can be found in the literature to discuss teachers' training needs for using drone technology in their teaching. In order to enable teachers to effectively integrate drone technology in their teaching, the first author conducted a study to examine teachers' readiness and to identify the training needs for using this new drone technology in education. This study aimed to explore the following research questions.

- To what extent, do teachers ready to use drone technology in their teaching?

- What trainings are required for teachers to apply drone technology in their teaching?

\section{METHOD}

In this study, the researchers intended to collect qualitative data from a specific group of participants. The case study approach of qualitative research was therefore applied to explore the research questions. The case study method helped to understand the case in depth and in its natural setting (Punch, 2011). The researchers were teacher trainers in a teacher training institute in Hong Kong. We aimed to identify the training needs of teachers for integrating drone technology in their teaching. Since this study focused on using drone technology in STEM education, ten pre-service teachers who were taking a bachelor program of information and communication technology in education were purposively invited to participate in this study. It was believed that they had better technology awareness. Another two pre-service teachers from General Studies and English subject expressed their interest on using drone technology in education were also included in this study. All of them did not have any experience to fly a drone prior to this study.

Similar to the study by Koehler and his colleagues (2004), a designed-based approach was adopted in order to explore the training needs of teachers. The underlying philosophy of a designed-based approach, including learning-by-doing, problem-based learning, and collaborative learning, exactly aligned with the rationale of this study. The participants were randomly divided into three groups under three assigned themes. The first group worked on the theme "DIY Drone in STEM Education" (DIY stands for Do It Yourself). The participants were given a set of drone components with installation instructions. They were requested to study how to assemble the drone from parts and how to fly the drone. This activity aimed to assess the technological knowledge of the participants. In the next stage, they were required to design a lesson plan for learners to learn the drone technology and to understand the general applications of a drone. The theme of the second group was "Programmable Drone in STEM Education". This group focused on the programmability affordance of a drone. The participants were given a drone that its flight path could be controlled by a user-created computer program. After studying the controlling features of the drone, the participants were required to design a lesson plan for learners to learn computer programming concepts using that drone. The third group worked on the theme "Aerial Photography/Videography in STEM Education". The participants were given a drone that equipped with a camera. This group was required to think about how to apply the photo/video-taking feature of a drone to support students' learning in STEM education. All the learning design target to learners from upper primary to lower secondary school level.

The lesson plans designed by three groups of participants were subsequently analyzed to understand their readiness and training needs regarding using drone technology in STEM education. The model of technological pedagogical content knowledge (TPCK) suggested by Mishra and Koehler (2006) was adopted as the analytical framework (Figure 1) since this study aimed to explore teachers' readiness to use drone technology in their teaching. The components of the TPCK model are stated in Table 1. The researchers examined the contents of the lesson plan and to assess to what extent the participants were equipped with TPCK knowledge for using drone technology in their teaching. 
Table 1. Components of TPCK model (Mishra \& Koehler, 2006, p. 1026-1029)

\begin{tabular}{|l|l|}
\hline Component & Knowledge \\
\hline Content Knowledge (CK) & Knowledge about the actual subject matter that is to be learned or taught. \\
\hline $\begin{array}{l}\text { Pedagogical Knowledge } \\
\text { (PK) }\end{array}$ & $\begin{array}{l}\text { Knowledge about the processes and practices or methods of teaching and } \\
\text { learning. }\end{array}$ \\
\hline $\begin{array}{l}\text { Technological Knowledge } \\
\text { (TK) }\end{array}$ & $\begin{array}{l}\text { Knowledge about standard technologies, such as books, chalk and black- } \\
\text { board, and more advanced technologies, such as the Internet and digital } \\
\text { video. }\end{array}$ \\
\hline $\begin{array}{l}\text { Pedagogical Content } \\
\text { Knowledge (PCK) }\end{array}$ & $\begin{array}{l}\text { Knowledge about what teaching approaches fit the content and how ele- } \\
\text { ments of the content can be arranged for better teaching. }\end{array}$ \\
\hline $\begin{array}{l}\text { Technological Content } \\
\text { Knowledge (TCK) }\end{array}$ & $\begin{array}{l}\text { Knowledge about the manner in which technology and content are recip- } \\
\text { rocally related. }\end{array}$ \\
\hline $\begin{array}{l}\text { Technological Pedagogical } \\
\text { Knowledge (TPK) }\end{array}$ & $\begin{array}{l}\text { Knowledge of the existence, components, and capabilities of various } \\
\text { technologies as they are used in teaching and learning settings, and con- } \\
\text { versely, knowing how teaching might change as a result of using particular } \\
\text { technologies. }\end{array}$ \\
\hline $\begin{array}{l}\text { Technological Pedagogical } \\
\text { Content Knowledge } \\
\text { (TPCK) }\end{array}$ & $\begin{array}{l}\text { Understanding of the representation of concepts using technologies; ped- } \\
\text { agogical techniques that use technologies in constructive ways to teach } \\
\text { content; knowledge of what makes concepts difficult or easy to learn and } \\
\text { how technology can help redress some of the problems that students face; } \\
\text { knowledge of students' prior knowledge and theories of epistemology; } \\
\text { and knowledge of how technologies can be used to build on existing } \\
\text { knowledge and to develop new epistemologies or strengthen old ones. }\end{array}$ \\
\hline
\end{tabular}

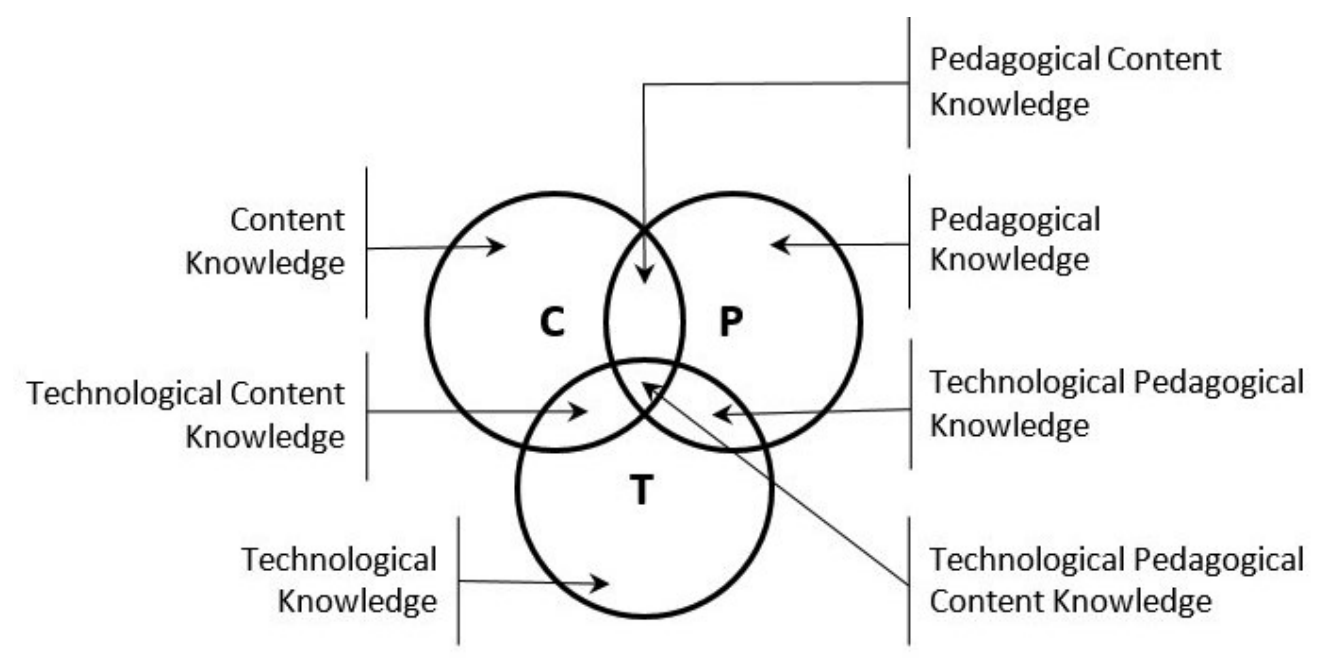

Figure 1. Technological Pedagogical Content Knowledge (TPCK) Model 


\section{RESULTS}

The performance of the participants (the pre-service teachers) was analyzed in a group basis. The elements in the created lesson plans were assessed to verify their competence in different dimensions of the TPCK framework.

\section{GROUP 1: DIY DRONE IN STEM EDUCATION}

The participants in this group successfully assembled the given DIY drone and flew it. It reflected that it is not a difficult task for them to assemble a drone from parts as long as a clear installation guide is given. It also suggests that the pre-service teachers already had a satisfactory level of technological knowledge. Regarding the lesson plan, they designed a double-lesson for learners of junior secondary level to learn drone technology and its applications. The learning objectives were to enable learners to:

- distinguish different types of drone and its applications in our daily life,

- understand the basic aerodynamic principles of a drone,

- discern different components of a drone and its functions,

- fly a drone, and

- understand the importance of designing a flight path.

Since a drone is a newly developed technology, it is anticipated that learners may lack relevant knowledge. The first three objectives are therefore considered appropriate since it aims to provide fundamental knowledge of drone technology. It suggests that the participants had good technological content knowledge to identify appropriate learning objectives for learners. In order to let learners have a better understanding on drone technology and its applications in our daily life, the design of the lesson includes the delivery of lectures with related contents for enhancing knowledge in the cognitive domain. It indicates that the participants had a satisfactory level of pedagogical content knowledge. To better understand the mechanism of a drone, an indispensable learning experience is to let learners practically fly a drone. In the lesson, a demonstration to fly a drone is provided and the target learners are given an opportunity to fly a drone. These teaching methods were appropriately chosen since it aimed to enhance skills in the psychomotor domain and to let learners familiarize with the drone operation. It shows that the participants' technological pedagogical knowledge was good. However, the purpose of the last objective is quite ambiguous. As elaborated in the lesson plan, the participants actually intended to engage learners in a drone racing activity and learners are requested to design a flight path. The last objective was actually related to a learning process instead of a learning objective. As reflected in this evidence, the participants might have difficulty to recognize what learners should learn regarding the drone technology. It suggests that the participants still required to enrich technological content knowledge of drone technology to understand what are valuable to learn.

\section{GROUP 2: PROGRAMMABLE DRONE IN STEM EDUCATION}

The second group was given a drone that its flight path can be specified by a user-created program. The participants designed a lesson for learners of junior secondary level to learn computer programming concepts using the drone. The objectives of the lesson were to enable the learners to:

- demonstrate the default operation of a programmable drone,

- identify characteristic of iteration concept by a programmable drone,

- demonstrate iterate operation by a programmable drone, and

- understand the importance of iteration in programming.

As reflected in the contents of the lesson plan, the lesson actually aimed to let learners have an understanding of the default operation of the programmable drone at the beginning of the lesson using a video clip. However, the participants inappropriately chose the action verb "demonstrate" in the 
first objective to express the meaning of "understand" or "describe". It suggests that the participants were still weak in pedagogical knowledge for stating an appropriate lesson objective. Regarding the last three objectives, the lesson aimed to let learners acquire the concept of iteration (content knowledge) by instructing a drone to fly according to a program with an iteration structure (technological pedagogical knowledge). It gives a piece of evidence to show that the participants in this group had good technological pedagogical content knowledge.

\section{GROUP 3: AERIAL PHOTOGRAPHY/VIDEOGRAPHY IN STEM EDUCATION}

The researchers provided a drone with an attached camera to this group. The participants were required to design lessons that apply the photo/video-taking feature of a drone in the teaching of STEM subjects. In their design, learners of upper primary level are instructed to consolidate the learning of perimeter and area in a real-world setting using a drone. The learning activity to compute the perimeter and area of a basketball court is illustrated in Figure 2. The first step is to let the drone takeoff and fly above point A of the basketball court. Next, the drone is moved to the same level above point $\mathrm{B}$ and then point $\mathrm{D}$. The camera is set vertically downward to make sure that the drone is exactly above point $B$ and point $D$. The horizontal distance of $A B$ and $A D$, detected by the embedded global positioning system function, are retrieved from the control panel of the drone. The perimeter and area of the basketball court can then be computed based on the values of $A B$ and $A D$.

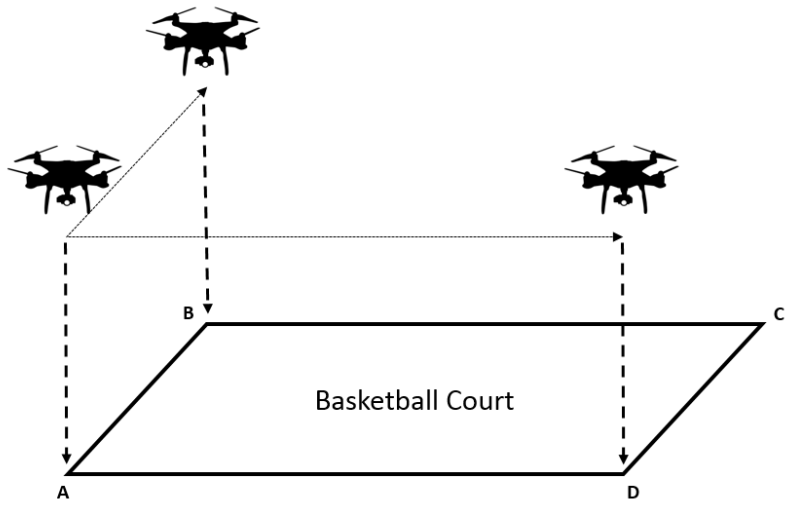

Figure 2. Learning activity to consolidate the learning of perimeter and area using a drone

The design of the learning activity could be regarded as in good quality since it appropriately applied drone technology to consolidate the learning of mathematical concepts (perimeter and area) in a realworld setting. The participants demonstrated their good technological pedagogical content knowledge in the design. However, there was an inadequacy in the writing of learning objectives of this lesson. As shown in the lesson plan, the lesson aimed to enable learners to:

- measure a figure,

- calculate the area and perimeter,

- apply the mathematical concept in real-world,

- control the drone,

- develop a technological sense, and

- attempt to use more technological devices.

The first three objectives could be considered appropriate since this lesson aimed to consolidate learners' mathematical concepts in a real-world setting. However, the fourth objective seemed not an appropriate objective since "to control a drone" was actually the learning process of this lesson instead of the ultimate goal. The last two objectives were very vague and not that relevant since this lesson focused on the learning of mathematical concepts. It suggests that the participants were weak in the content knowledge of mathematics. They could not accurately grasp the learning objective of the 
lesson. A summary of the participants' competence in three groups to apply drone technology in teaching is shown in Table 2 .

Table 2. Participants' competence to apply drone technology in teaching

\begin{tabular}{|l|l|l|l|l|l|l|l|l|}
\hline Group & Theme & TK & PK & CK & TPK & TCK & PCK & TPCK \\
\hline 1 & $\begin{array}{l}\text { DIY Drone in STEM } \\
\text { Education }\end{array}$ & Satisfactory & & & Good & $\begin{array}{l}\text { Need to } \\
\text { improve }\end{array}$ & Satisfactory & \\
\hline 2 & $\begin{array}{l}\text { Programmable Drone } \\
\text { in STEM Education }\end{array}$ & $\begin{array}{l}\text { Need to } \\
\text { improve }\end{array}$ & & & & Good \\
\hline 3 & $\begin{array}{l}\text { Aerial Photog- } \\
\text { raphy/Videography in } \\
\text { STEM Education }\end{array}$ & & & $\begin{array}{l}\text { Need to } \\
\text { improve }\end{array}$ & & & Good \\
\hline
\end{tabular}

\section{DISCUSSION AND CONCLUSIONS}

As highlighted by Carr and his colleagues (1998), technology itself cannot change the practice of teaching and learning. Simply providing technology to teachers is not sufficient. It depends on teachers' knowledge of the technology and how they appropriately exploit the technology to initiate the change. However, the context of teaching is a dynamic environment that is very complicated. It involves knowledge of various domains (Mishra \& Koehler, 2006). In this connection, this study attempted to assess teachers' readiness and their training needs using the TPCK framework regarding the use of drone technology in education. As reflected by the results, the participants (the pre-service teachers) of this study demonstrated a satisfactory level of competence in the areas of technological knowledge (TK) and pedagogical content knowledge (PCK). They were good in technological pedagogical knowledge (TPK) and technological pedagogical content knowledge (TPCK). These favorable results suggest that the pre-service teachers, to a large extent, have sufficient competence to master the skills and knowledge of drone technology and to integrate it into their teaching.

However, the pre-service teachers in this study demonstrated weak performance in some aspects and they are still required to improve their competence for effectively integrating drone technology in their teaching. For example, although the pre-service teachers in Group 1 had quite good overall performance, results show that they still needed to strengthen their technology content knowledge of a drone in order to more accurately identify the appropriate learning objective. On the other hand, the pre-service teachers in Group 2 occasionally got confused with the pedagogy applied in the teaching process and that stated in the lesson objective. It indicates the need for more training on pedagogical knowledge. In Group 3, although the pre-service teachers were able to design a lesson with good use of drone technology, they were required to strengthen the subject content knowledge. It is critical since a teacher can help learners to acquire related knowledge only if they know the subject well (Ball, Thames, \& Phelps, 2008). These results aligned with the argument that good teaching requires an understanding of how technology relates to the pedagogy and content (Mishra \& Koehler, 2006).

With the development of drone technology, it has been increasingly used as a tool to enhance teaching and learning effectiveness. The movability, programmability and equipment-carrying affordance of a drone bring opportunities to change the practices of classroom teaching. This study assessed the readiness of a group of pre-service teachers to integrate drone technology in teaching and identified the areas of training needs. Future research may explore the readiness of in-service teachers of using drone technology in their teaching, and to address the safety issue and ethical issue of using a drone in education. 


\section{REFERENCES}

Ball, D. L., Thames, M. H., \& Phelps, G. (2008). Content knowledge for teaching: What makes it special? Journal of Teacher Education, 59(5), 389-407. https://doi.org/10.1177/0022487108324554

Birtchnell, T., \& Gibson, C. (2015). Less talk more drone: Social research with UAVs. Journal of Geography in Higher Education, 39(1), 182-189. https://doi.org/10.1080/03098265.2014.1003799

Carnahan, C., Zieger, L., \& Crowley, K. (2016). Drones in education: Let your students' imagination soar. Arlington, Virginia: International Society for Technology in Education.

Carr, A. A., Jonassen, D. H., Litzinger, M. E., \& Marra, R. M. (1998). Good ideas to foment educational revolution: The role of systematic change in advancing situated learning, constructivism, and feminist pedagogy. Educational Technology, 38(1), 5-15. Retrieved from https://www.jstor.org/stable/44428442

Department of Defense (2018). DOD Dictionary of military and associated terms. United States.

Dronepedia. (2017). Types of drones. Retrieved November 29, 2018, from Dronepedia: https://dronepedia.xyz/5-different-types-of-drones

Guzey, S. S., \& Roehrig, G. H. (2012). Integrating educational technology into the secondary science teaching. Contemporary Issues in Technology and Teacher Education, 12(2), 162-183. Retrieved from https://www.learntechlib.org/p/39130/paper_39130.pdf

Jordan, B. R. (2015). A bird's-eye view of geology: The use of micro drones/UAVs in geologic fieldwork and education. GSA Today, 25(7), 42-43. https://doi.org/10.1130/GSATG232GW.1

Kim, B.-H. (2016). Development of young children coding drone using block game. Indian Journal of Science and Technology, 9(44), 1-5. https://doi.org/10.17485/ijst/2016/v9i44/105175

Koehler, M. J., Mishra, P., Yahya, K., \& Yadav, A. (2004). Successful teaching with technology: The complex interplay of content, pedagogy, and technology. Proceedings of SITE 2004--Society for Information Technology \& Teacher Education International Conference (pp. 2347-2354). Atlanta, GA, USA: Association for the Advancement of Computing in Education. Retrieved from https://www.learntechlib.org/p/14799/

Lee, D. (2016). Thermal imaging drones. $L A W$ and ORDER, 20-22. Retrieved from http://content.yudu.com/web/y5b2/0A2qjxz/LawAndOrderMay2016/flash/resources/index.htm?refUrl =http $\% 253 \mathrm{~A} \% 252 \mathrm{~F} \% 252 \mathrm{Fwww}$.hendonpub.com $\% 252 \mathrm{Flaw}$ and order

Lee, D. (2018). China's bungled drone display breaks world record. Retrieved November 29, 2018, from BBC News: https://www.bbc.com/news/technology-43982522

Mishra, P., \& Koehler, M. J. (2006). Technological pedagogical content knowledge: A framework for teacher knowledge. Teachers College Record, 108(6), 1017-1054. https://doi.org/10.1111/j.1467-9620.2006.00684.x

Murch, A. M., Paw, Y. C., Pandita, R., Li, Z., \& Balas, G. J. (2011). A low cost small UAV flight research facility. In F. Holzapfel, \& S. Theil, Advances in Aerospace Guidance, Navigation and Control (pp. 29-40). Berlin, Heidelberg: Springer. https://doi.org/10.1007/978-3-642-19817-5 3

Pearcy, M. (2015). "They're always over us" - Teaching about drones. The Social Studies, 106(3), 126-137. https://doi.org/10.1080/00377996.2015.1029606

Petrinjak, L. (2016). Using drones to enhance STEM learning. NSTA Reports, 27(8), 8-9.

Preble, B. C. (2015). A case for drones. Technology and Engineering Teacher, 74(7), 24-29. Retrieved from https://search.proquest.com/openview/489aa60e96ffca49145034f8a7087e46/1?pqorigsite $=$ gscholar \&cbl $=34845$

Punch, K. F. (2011). Introduction to research methods in education. London: SAGE Publications Ltd.

Romano, M. (2014). Drones as lifesavers. The Science Teacher, 81(3), 14.

Stohlmann, M., Moore, T. J., \& Roehrig, G. H. (2012). Considerations for teaching integrated STEM education. Journal of Pre-College Engineering Education Research, 2(1), 28-34. https://doi.org/10.5703/1288284314653 
Strimel, G. J., Bartholomew, S. R., \& Kim, E. (2017). Engaging children in engineering design through the world of quadcopters. Children's Technology and Engineering, 7-11. Retrieved from https://www.iteea.org/Publications/Journals/ESCJournal/CTE-May2017.aspx

\section{ACKNOWLEDGEMENT}

This project was supported by The Education University of Hong Kong.

\section{BIOGRAPHIES}

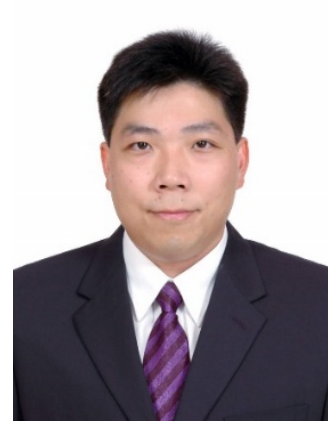

Dr. Wing Shui $\mathrm{Ng}$ is a Lecturer in The Education University of Hong Kong. He has extensive involvement in computer education in Hong Kong. He has continuously engaged in international research-related activities. Currently, he serves as an Associate Editor-in-Chief of The International Journal of Doctoral Studies (IJDS), a Reviewer of papers submitted to international journals and conferences, and a Speaker as well as a Committee Member of international conferences. He has published a number of academic articles, including journal papers, conference papers, book chapters, and an edited book, in the areas of Educational Assessment and Information Technology in Education.

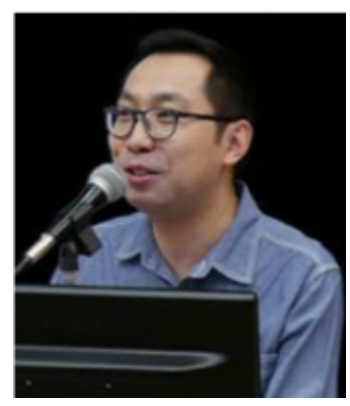

Dr. Gary Cheng is the Associate Head and Associate Professor in the Department of Mathematics and Information Technology at the Education University of Hong Kong. He has over 18 years of teaching experience in higher education. His research interests include e-learning, learning management systems, electronic portfolio, automated systems for teaching and learning, and learning analytics. 